Research Article

\title{
Experimental and Numerical Study on the Behavior of Energy Piles Subjected to Thermal Cycles
}

\author{
Kang Fei $(\mathbb{D})$ and Di Dai $(\mathrm{C}$ \\ Institute of Geotechnical Engineering, Yangzhou University, Yangzhou 225127, China \\ Correspondence should be addressed to Kang Fei; kfei@yzu.edu.cn
}

Received 9 May 2018; Accepted 16 August 2018; Published 23 September 2018

Academic Editor: Arturo Gonzalez

Copyright (c) 2018 Kang Fei and Di Dai. This is an open access article distributed under the Creative Commons Attribution License, which permits unrestricted use, distribution, and reproduction in any medium, provided the original work is properly cited.

\begin{abstract}
A laboratory-scale model test is conducted to improve the understanding of the effects of thermal cycles on the mechanical behavior of energy piles. The model pile is composed of cement mortar and dry sand with a relative density of $30 \%$ is used for the model ground. After applying the working load to the pile head, the pile is subjected to three thermal cycles with a magnitude of $15^{\circ} \mathrm{C}$. The measured temperature response and mechanical behavior are analyzed and used to validate the proposed numerical approach. In the numerical analysis, the temperature variation due to thermal cycles is calculated using uncoupled heat transfer analysis. Then, the computed temperature field is used as the boundary condition in the sequence stress analysis. A series of numerical sensitivity analyses are carried out using the sequentially coupled method to investigate the long-term performance of energy piles under different soil and pile head restraint conditions. The numerical results suggest that the restraint condition at the pile head plays an important role in the mechanical response of energy piles. The ultimate pile resistance after thermal cycles does not decrease significantly. The accumulation of settlement of the free head pile and the reduction in the axial force of the restrained head pile should be considered in the design.
\end{abstract}

\section{Introduction}

Energy piles are pile foundations equipped with fluid carrying pipes to exchange heat with the surrounding medium. Owing to the temperature change, the energy pile expands or contracts during the thermal operation. Because of the complex pile-soil interaction under thermomechanical loading, the mechanical behavior of energy piles is quite different from that of conventional piles. The in situ test results reported by Brandl [1], Laloui et al. [2], and BourneWebb et al. [3] indicate that the heating of the pile resulted in an additional pile compressive stress. In the case of cooling, an additional tensile stress was observed. To interpret the change in the pile stress and shaft friction during heating and cooling, Amatya et al. [4] developed a simplified load transfer mechanism for energy piles. They suggested that the mechanical behavior of energy piles was mainly dependent on the thermal load, soil type, and end-restraint conditions. The rate of change in the pile stress was approximately
$100 \mathrm{kPa} /{ }^{\circ} \mathrm{C}$ to $300 \mathrm{kPa} /{ }^{\circ} \mathrm{C}$. As the temperature change in energy piles generally ranges from $-15^{\circ} \mathrm{C}$ to $+20^{\circ} \mathrm{C}$, the risk of structural damage due to the temperature variation is relatively small [5]. The effect of the temperature variation on pile settlement has become a research focus.

It is worth noting that energy piles experience seasonal expansion and contraction throughout the service period. As a result, the surrounding soil is subjected to cyclic loading, which may have an important impact on the mechanical behavior of energy piles. Because in situ tests are expensive and time-consuming, the performance of energy piles subjected to thermal cycles has typically been studied by physical modeling or numerical simulations. Kalantidou et al. [6] investigated the effects of thermal cycles on pile settlement via a series of small-scale tests in dry sand. In the study, four tests with different axial pile head loads were performed. For each test, two thermal cycles were applied. It was shown that when the mechanical load was high, the irreversible pile settlement after the thermal cycles could not 
be ignored. One possible reason for the irreversible settlement is that the thermal deformation of the energy pile may modify the stress state of the surrounding soil and induce plastic strain. By using a similar experimental procedure and equipment, Yavari et al. [7] also reported that significant cumulative settlement can be observed at high axial loads. On the basis of the measured strain and the deduced axial force along the pile, the mobilized skin friction was found to change significantly during the thermal cycles. Nguyen et al. [8] adopted a relatively high number of thermal cycles (30 cycles). The additional pile stress induced by heating did not fully recover during the subsequent cooling phase. As a result, the axial force after 30 thermal cycles was higher than the initial value.

The centrifuge method has been used successfully in the geotechnical research field as the stress field of the soil can be reproduced reasonably. Although the scale factor of the heat transfer is not the same as the geometric one, the centrifuge experiment can also provide useful information of the thermomechanical behavior of energy piles $[9,10]$. Stewart and McCartney [11] investigated the transient thermomechanical response of an end-bearing energy pile embedded in unsaturated bonny silt. Owing to the strong endrestraint condition, no irreversible settlement was observed. The thermally induced heave displacement at the pile head decreased slightly during successive thermal cycles. $\mathrm{Ng}$ et al. [12] performed centrifuge tests on floating energy piles subjected to heating and cooling cycles in clay. They observed that, for the piles in lightly and heavily overconsolidated clay, the cumulative pile settlements after five thermal cycles were $3.8 \%$ and $2.1 \%$ of the pile diameter, respectively, which are significantly larger than those caused by the static working load. It seems that the soil type and the end-restraint conditions have important effects on the cyclic behavior of energy piles.

Loria et al. [13] conducted a series of finite element analyses to investigate the mechanical behavior of energy piles under different thermal and mechanical loads. By comparing with the centrifuge test data, the finite element method was validated to be able to capture key characteristics of energy piles only subjected to only one single thermal cycle, even using a relatively simple soil constitutive model (the Mohr-Coulomb perfect elastoplasticity model). A similar conclusion was drawn by Jeong et al. [14] and Di Donna et al. [15]. Saggu and Chakrabotry [16] investigated the effects of thermal cycles on the pile capacity and displacement using finite element analyses. In their study, the sand behavior was also described by the Mohr-Coulomb model. They suggested that the pile head settled after the initial thermal cycles and then heaved during the subsequent thermal cycles. This finding is different to that observed in the model tests $[6,8]$, in which an accumulated downward displacement of the pile was evident. As pointed out by Suryatriyastuti et al. [17], the cyclic hardening/softening behavior of the pile-soil interface and the soil should be considered in the long-term performance analysis of energy piles. By using a cyclic elastoplastic interface model, Suryatriyastuti et al. [18] concluded that the pile capacity may be degraded with thermal cycles owing to repetitive stress reversal. Fei et al. [19] pointed that the soil dilatancy plays an important role in the change of the shaft resistance after thermal cycles. The finite element analysis carried out by $\mathrm{Ng}$ et al. [20] showed that the horizontal stress may decrease significantly with thermal cycles if the soil contraction during cyclic shearing is not negligible. The consequent additional settlement and the shaft resistance reduction should be considered. These numerical results need to be further validated experimentally.

At present, the understanding of the long-term behavior of energy piles remains limited. To obtain insights into the effects of thermal cycles on the settlement and the capacity of energy piles, a laboratory-scale model test is performed. The measured temperature response and mechanical behavior are analyzed and used to validate a finite element model. Then, a series of numerical sensitivity analyses are carried out to investigate the impacts of thermal cycles on the mechanical behavior of energy piles with different soil and pile head restraint conditions. The focus is on the thermally induced displacement, thermally induced axial force, shear stress response at the pile-soil interface, and pile bearing capacity after thermal cycles.

\section{Experimental Program}

2.1. Test Materials. The experimental setup is shown in Figure 1 . The experiments were performed in a steel box with the dimensions of $1 \times 1 \times 1.5 \mathrm{~m}$ (length $\times$ width $\times$ height). The model pile was $1000 \mathrm{~mm}$ long and $100 \mathrm{~mm}$ in diameter and was made of cement mortar. The embedded depth of the pile was $900 \mathrm{~mm}$. To control the pile temperature, a U-type polyethylene pipe of $16 \mathrm{~mm}$ outer diameter and $13 \mathrm{~mm}$ inner diameter was embedded in the pile. The pile was heated or cooled to the desired temperature by cycling the water from a temperature-controlled bath.

The soil used in the study was dry Yangzhou sand. The particle-size distribution of the sand is shown in Figure 2. The coefficient of uniformity and coefficient of curvature were 3.3 and 0.98 , respectively. The minimum and maximum dry densities were 1.41 and $1.74 \mathrm{~g} / \mathrm{cm}^{3}$, respectively. The specific gravity of the sand was 2.70 .

The model ground was prepared by "raining" the dry sand in the model box and by compacting it to achieve a relative density of $30 \%$. A series of triaxial tests were carried out to characterize the sand behavior at the same relative density. After filling the sand to a thickness of $450 \mathrm{~mm}$, the model pile was fixed in the center of the model box using a temporary support. Then, the filling process was conducted to achieve a total sand layer thickness of $1350 \mathrm{~mm}$.

2.2. Test Process. Two tests were performed in the study. In the first test, the pile was vertically loaded to failure. The ultimate pile resistance was determined based on the measured load-displacement relationship.

In the second test, the pile was first loaded to a working load of $0.8 \mathrm{kN}$. After the mechanical loading process, three thermal cycles were applied to the pile. The time duration of each cycle was $24 \mathrm{~h}$. The pile temperature was first increased 
by $15^{\circ} \mathrm{C}$ by cycling the hot water in the heat pipe. After 30 min of cycling, the fluid circulation was stopped to allow the pile temperature to decrease naturally to the indoor temperature.

2.3. Instrumentation. The vertical load on the pile head was applied by rigid steel blocks. Two symmetrically placed dial gauges (D1-D2) were used to measure the settlement at the pile head. Six strain gauges (S1-S6) were installed at $150 \mathrm{~mm}$ intervals along the pile shaft, beginning at a depth of $150 \mathrm{~mm}$ from the pile top. Four temperature sensors (T1-T4) were used to measure the pile temperature. Another nine temperature sensors (T5-13) were installed in the soil at different distances from the center of the pile (Figure 1).

It should be noted that the stress level in the $1 \mathrm{~g}$ model test was quite lower than that of the prototype system. As a result, the stress-dependent mechanical behavior of the sand is different from the actual case. Hence, the aim of the test is not to predict the behavior of a prototype but to investigate the influences of the cyclic thermal loading on the performance of energy piles and the mechanism involved.

\section{Numerical Simulation of the Model Test}

3.1. Numerical Approach. In this study, the numerical analyses of energy piles were performed using ABAQUS software. As the temperature response can be regarded as independent of the stress/deformation field, a sequentially coupled technique was used in the study. First, the temperature was calculated through an uncoupled heat transfer analysis. Then, the position varied and time-dependent temperatures were read into the sequence stress analysis as predefined fields. The thermal strain and the effect on the mechanical response were accounted for by including the thermal expansion coefficient in the material property definition.

3.2. Initial and Boundary Conditions. The numerical analyses were carried out under three-dimensional conditions. Considering the symmetry of the problem, only one quarter of the model was included in the computation. Both the vertical and horizontal displacements were fixed on the bottom of the model domain, and only horizontal displacements were constrained on the lateral sides.

The initial stresses due to gravity were calculated by the bulk unit weight and the coefficient of earth pressure at rest, $K_{0}$. As the horizontal soil stress was not measured in the test, the value of $K_{0}$ was back-calculated from the static loadsettlement response of the pile. After some trials, $K_{0}$ was chosen as 1.0. This value is close to that suggested by Desai et al. [21] for a model ground prepared using a similar sampling method.

The initial temperature of the analysis domain was $16^{\circ} \mathrm{C}$. The main objective of this study is to understand the effect of cyclic thermal loading on the mechanical behavior of energy piles; thus, the complicated heat transfer process between the heat transfer fluid, pipe, pile, and soil was simplified by imposing a time-dependent temperature on the pile. The measured temperature history of the pile (T2) shown in Figure 3 was used as the boundary condition in the analysis. At the boundaries of the analysis region, the surface film condition with a film coefficient of $10 \mathrm{~W} /\left(\mathrm{m}^{2 \circ} \mathrm{C}\right)$ was specified to account for the heat transfer between the wall of the steel box and the air.

3.3. Material Models and Parameters. The pile was considered thermoelastic and was modeled as a linear elastic material. The relevant parameters are given in Table 1 .

The thermal characteristics of the dry sands considered in this study were evaluated considering the volumetric fractions of the solid soil particles and the pore air. The adopted thermal constants listed in Table 2 were estimated based on typical values for sand particles.

To model the stress-strain relationship of the sand, both the Mohr-Coulomb (MC) model and the bounding surface (BS) model developed by Bardet [22] were used. The differences in the numerical results of the two models were used to indicate the effects of the cyclic behavior of the sand.

In ABAQUS, the yield surface of the MC model is expressed as

$$
f=R_{\mathrm{mc}} q-p \tan \varphi-c=0,
$$

where $R_{\mathrm{mc}}=((1 / \sqrt{3}) \cos \varphi \sin (\theta+(\pi / 3)))+((1 / 3) \cos (\theta+$ $(\pi / 3)) \tan \varphi) ; \varphi$ is the friction angle of the soil; $c$ is the soil cohesion; $p$ is the mean pressure; $q$ is the deviatoric stress; and $\theta$ is the deviatoric polar angle, $\cos 3 \theta=$ $(3 \sqrt{3} / 2)\left(J_{3} / J_{2}^{3 / 2}\right)$, where $J_{2}$ and $J_{3}$ are the second and third invariants of the deviatoric stress, respectively.

Inside the yield surface, the strain increment is elastic and is related to Young's modulus, $E$, and Poisson's ratio, $v$. A nonassociated plastic flow function was used to determine the plastic strain increment for the state on the yield surface. The adopted flow potential function is a hyperbola in the meridional stress plane and an ellipse in the deviatoric stress plane. The shapes of the hyperbola and the ellipse are controlled by the dilation and friction angles, respectively.

Although the MC model can capture the soil failure behavior reasonably, it has a limited capacity to simulate the soil deformation behavior, especially in cases where the magnitude and direction of the load change significantly.

To simulate the accumulation of irreversible strain during cyclic loadings, the BS model was implemented in ABAQUS and used in the analysis. In the BS model, the elastic strain increment is calculated using a nonlinear bulk modulus, $B$, and a constant Poisson's ratio, $v$. The bulk modulus is given as

$$
B=\frac{1+e_{0}}{\kappa} p
$$

where $e_{0}$ is the initial void ratio and $\kappa$ is the slope of the isotropic unloading line in the $e-\ln p$ plane. According to this equation, the bulk modulus approaches zero for a relatively small confining stress, which is not consistent with the real behavior. As suggested by Brinkgreve [23], the following correlation was used in this study: 


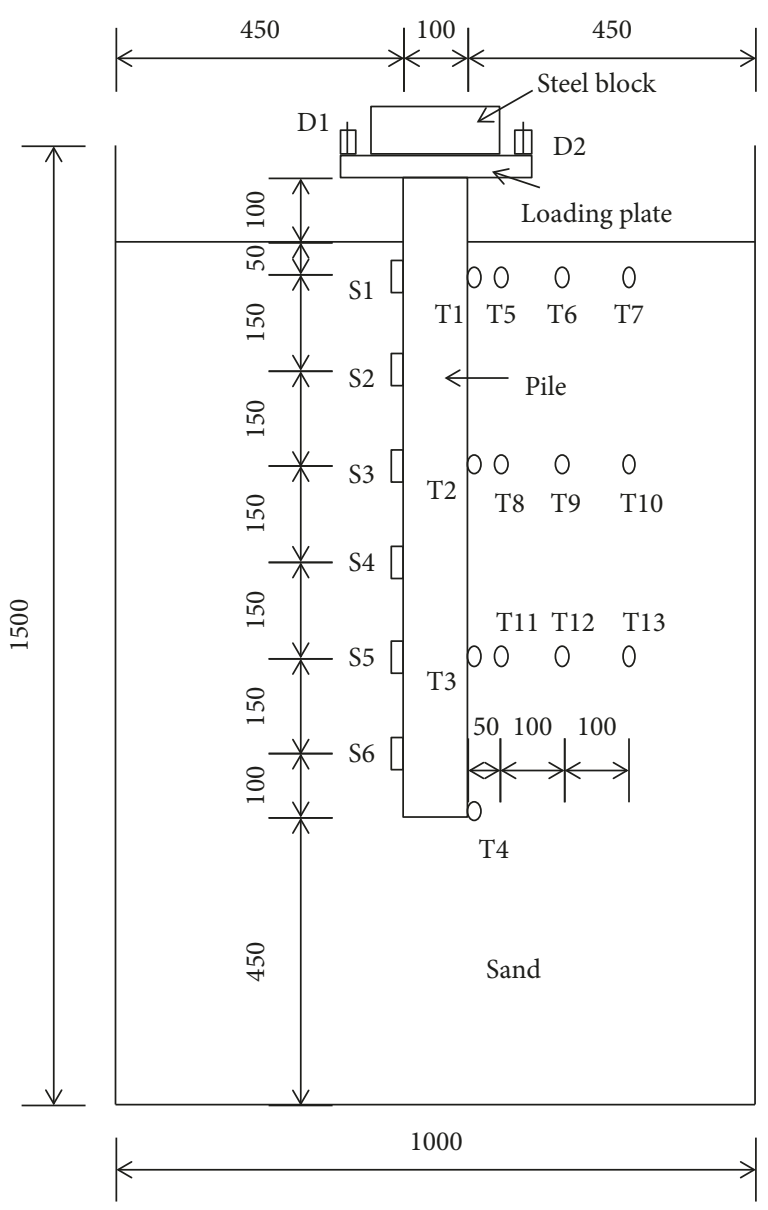

D Displacement gauge

(]) Strain gauge

0 Temperature gauge

Figure 1: Experimental setup.

$$
E=E^{\mathrm{ref}} \sqrt{\frac{\sigma_{3}^{\prime}}{p^{\mathrm{ref}}}}
$$

where $E^{\text {ref }}$ is the elastic modulus at the reference stress $p^{\text {ref }}$ ( $100 \mathrm{kPa}$ in this study) and $\sigma_{3}^{\prime}$ is the effective confining stress.

The direction of the plastic strain increment is the same as that of the image stress on the bounding surface. The bounding surface is expressed as

$$
f=\left(\frac{p-A}{\rho-1}\right)^{2}+\left(\frac{q}{M}\right)^{2}-A^{2}=0,
$$

where $\rho$ is the ellipse aspect ratio, $A$ is the mean pressure at the ellipse summit, and $M$ is the slope of the critical line in the $p-q$ space. The value of $M$ is dependent on the deviatoric polar angle:

$$
M=\frac{2 M_{\mathrm{c}} M_{\mathrm{e}}}{M_{\mathrm{c}}+M_{\mathrm{e}}-\left(M_{\mathrm{c}}-M_{\mathrm{e}}\right) \cos 3 \theta},
$$

where $M_{\mathrm{c}}$ and $M_{\mathrm{e}}$ are the slopes of the critical line in compression and extension, respectively:

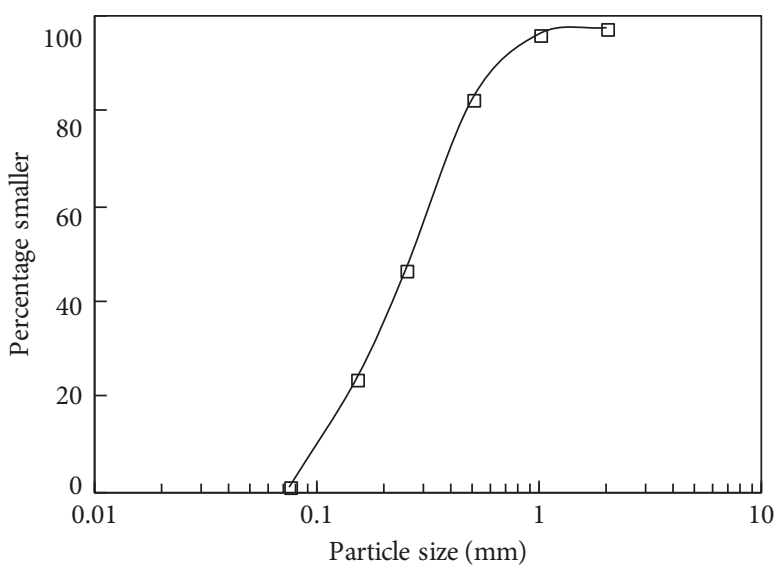

Figure 2: Particle-size distribution of the sand.

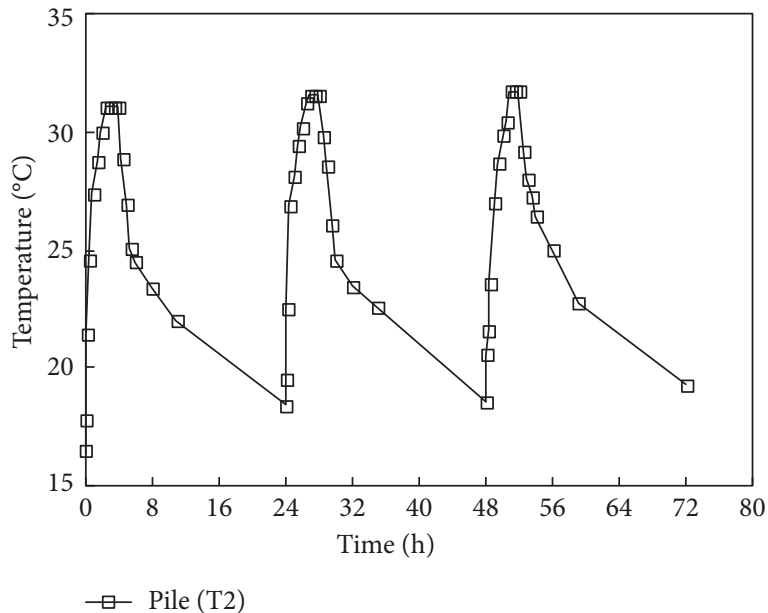

FIgURE 3: Measured temperature variation of the pile.

$$
\begin{aligned}
& M_{\mathrm{c}}=\frac{6 \sin \varphi_{\mathrm{c}}}{3-\sin \varphi_{\mathrm{c}}}, \\
& M_{\mathrm{e}}=\frac{6 \sin \varphi_{\mathrm{e}}}{3+\sin \varphi_{\mathrm{e}}},
\end{aligned}
$$

where $\varphi_{\mathrm{c}}$ and $\varphi_{\mathrm{e}}$ are the residual friction angles measured in conventional compression and tension triaxial tests, respectively.

The hardening of the bounding surface is controlled by the plastic volumetric strain:

$$
A=\exp \left(\frac{\Gamma-e-\kappa \ln p}{\lambda-\kappa}\right)
$$

where $\Gamma$ is the void ratio at the critical state when $p=100 \mathrm{kPa}, e$ is the current void ratio, and $\lambda$ is the slope of the critical state line in $e-\ln p$ space.

The plastic modulus, $H$, was selected as

$$
H=H_{\mathrm{b}}+\frac{1+e_{0}}{\lambda-\kappa} \frac{\delta}{\delta_{\max }-\delta} h_{0} p\left\langle\frac{\eta_{\mathrm{p}}}{M_{\mathrm{c}}}-\frac{\eta}{M}\right\rangle,
$$


TABLE 1: Material parameters of piles.

\begin{tabular}{lcc}
\hline & Model pile & Concrete pile \\
\hline Density, $\rho\left(\mathrm{kg} / \mathrm{m}^{3}\right)$ & 2000 & 2500 \\
Thermal conductivity, $\lambda\left(\mathrm{W} / \mathrm{m}^{\circ} \mathrm{C}\right)$ & 0.9 & 2.0 \\
Specific heat, $C_{\mathrm{p}}\left(\mathrm{J} /{ }^{\circ} \mathrm{C}\right)$ & 1050 & 970 \\
Linear thermal expansion coefficient, $\alpha\left(10^{-6} /{ }^{\circ} \mathrm{C}\right)$ & 24.5 & 10 \\
Elastic modulus, $E(\mathrm{GPa})$ & 4 & 30 \\
Poisson's ratio, $v$ & 0.2 & 0.18 \\
\hline
\end{tabular}

TABLE 2: Material parameters of the sands.

\begin{tabular}{|c|c|c|c|c|}
\hline & & $\begin{array}{c}\text { Yangzhou sand } \\
\text { (test sand) }\end{array}$ & $\begin{array}{c}\text { Loose Sacramento } \\
\text { River sand }\end{array}$ & $\begin{array}{c}\text { Dense Sacramento } \\
\text { River sand }\end{array}$ \\
\hline \multirow{4}{*}{ Thermal parameters } & Dry density, $\rho_{\mathrm{d}}\left(\mathrm{kg} / \mathrm{m}^{3}\right)$ & 1490 & 1450 & 1670 \\
\hline & Thermal conductivity of soil particle, $\lambda\left(\mathrm{W} / \mathrm{m}^{\circ} \mathrm{C}\right)$ & 2.4 & 2.4 & 2.4 \\
\hline & Specific heat of soil particle, $C_{\mathrm{p}}\left(\mathrm{J} /{ }^{\circ} \mathrm{C}\right)$ & 930 & 930 & 930 \\
\hline & $\begin{array}{l}\text { Linear thermal expansion coefficient of soil particle, } \alpha \\
\left(10^{-6} /{ }^{\circ} \mathrm{C}\right)\end{array}$ & 10.0 & 10.0 & 10.0 \\
\hline \multirow{5}{*}{ MC model } & Elastic modulus, $E(\mathrm{MPa})$ & 3.34 & - & - \\
\hline & Poisson's ratio, $v$ & 0.3 & - & - \\
\hline & Cohesion, $c(\mathrm{kPa})$ & 0 & - & - \\
\hline & Friction angle, $\varphi\left(^{\circ}\right)$ & 30.6 & - & - \\
\hline & Dilation angle, $\psi\left({ }^{\circ}\right)$ & 0.0 & - & - \\
\hline \multirow{11}{*}{ BS model } & Initial void ratio, $e_{0}$ & 0.78 & 0.87 & 0.61 \\
\hline & Elastic swelling modulus, $\kappa$ & 0.01 & 0.01 & 0.0075 \\
\hline & Poisson's ratio, $v$ & 0.3 & 0.2 & 0.2 \\
\hline & Critical void ratio at $100 \mathrm{kPa}, \Gamma$ & 0.60 & 0.97 & 0.84 \\
\hline & Slope of the critical state line, $\lambda$ & 0.12 & 0.076 & 0.076 \\
\hline & Ellipse aspect ratio, $\rho$ & 2.0 & 2.2 & 1.65 \\
\hline & Residual friction angle in compression, $\varphi_{\mathrm{c}}\left({ }^{\circ}\right)$ & 30.6 & 34.6 & 36.2 \\
\hline & Residual friction angle in tension, $\varphi_{\mathrm{e}}\left({ }^{\circ}\right)$ & 30.6 & 34.6 & 36.2 \\
\hline & Peak friction angle, $\varphi_{\mathrm{p}}\left({ }^{\circ}\right)$ & 32.0 & 35.7 & 43.8 \\
\hline & Plastic modulus, $h_{0}$ & 1.0 & 2.0 & 2.0 \\
\hline & Elastic modulus at $100 \mathrm{kPa}, E^{\mathrm{ref}}(\mathrm{MPa})$ & 12.0 & 18.7 & 21.5 \\
\hline
\end{tabular}

where $H_{\mathrm{b}}$ is the plastic modulus at the image stress, which can be determined by the consistency condition; $\delta$ is the distance between the current stress state and its image point on the bounding surface; $\delta_{\max }$ is the largest possible distance; \langle\rangle is the Macaulay bracket operator; $\eta=q / p$ is the stress ratio; and $h_{0}$ and $\eta_{\mathrm{p}}$ are material constants. The constant $\eta_{\mathrm{p}}$ is related to the peak failure friction angle in the compression triaxial test:

$$
\eta_{\mathrm{p}}=\frac{6 \sin \varphi_{\mathrm{p}}}{3-\sin \varphi_{\mathrm{p}}} .
$$

The soil parameters are summarized in Table 2. Among these parameters, $v$ and $\rho$ were taken as typical values. $\kappa$ was calculated based on the isotropic loading-unloading test. $h_{0}$ was determined by best fitting the predicted and experimental results. The remaining parameters were obtained from standard drained triaxial tests at the confining stresses of 50,100 , and $200 \mathrm{kPa}$. The elastic modulus of the $\mathrm{MC}$ model was estimated using Equation (3) and the stress level at the middepth of the ground.

The soil-pile interface was modeled as a layer of thin elements, and the constitutive parameters were taken as the same as those for the surrounding sand.

\section{Comparison between Numerical and Test Results}

4.1. Load-Settlement Relationship. The computed and measured load-settlement relationships are compared in Figure 4. As shown, both the MC and BS models yield reasonable results. On the basis of the load-settlement curves, the ultimate pile resistance was found to be $1.35 \mathrm{kN}$ (MC model), $1.62 \mathrm{kN}$ (BS model), and $1.70 \mathrm{kN}$ (measured) by using the tangent method. In the tangent method, the value of the ultimate resistance is determined at the intersection of the tangents to the initial and final portions of the load-settlement curve.

One possible reason for the deviation between the predicted and measured results is that the model tests were conducted under the $1 \mathrm{~g}$ condition, and thus the soil stresses due to gravity were relatively small. At such low confining stress levels, the sand is expected to be dilative. During the loading process of the pile, the soil expansion due to shear was constrained by the rigid pile body. As a result, the horizontal stress at the pile shaft and the corresponding shaft resistance increased with loading until the critical state was 


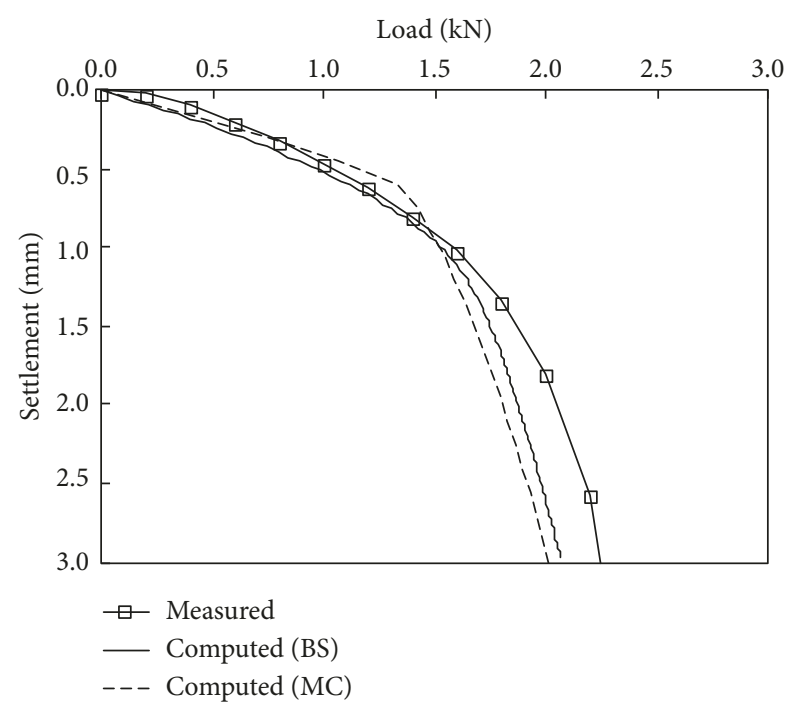

FIGURE 4: Load-settlement relationship.

reached. In the analysis with the MC model, the dilation angle was taken as zero to avoid the unrealistic volume dilatancy when shear failure occurs. Hence, the ultimate pile resistance was underestimated. In the analysis with the BS model, the state-dependent dilatancy can be simulated using the elliptic plastic potential. However, the parameters used in the analyses were obtained from the tests conducted at relatively high stresses, and thus the soil dilatancy behavior at low stress levels may not be represented very accurately.

4.2. Temperature Response. The measured temperature responses of the pile and soil are shown in Figure 5(a). The pile temperature increased continuously during the first heating process and reached $31.0^{\circ} \mathrm{C}$ after circulating the transfer fluid for approximately $2.5 \mathrm{~h}$. The soil temperatures were also observed to increase, but at lower rates. After the first heating, the peak temperatures at $1.0 \mathrm{D}, 2.0 \mathrm{D}$, and $3.0 \mathrm{D}$ (where $D$ is the pile diameter) from the centerline of the pile were $19.2,17.9$, and $16.9^{\circ} \mathrm{C}$, respectively. The observed time lag between the peak temperature of the soil and pile is an indication of the heat wave propagation. After each heating process, the energy pile was cooled naturally by stopping the fluid circulation. It is observed that the pile temperature decreased at a degressive rate. At the end of the first cooling phase, the pile temperature did not return to the initial value; a residual temperature increment of $2.4^{\circ} \mathrm{C}$ was observed. A similar pattern was observed for the soil temperature. These overall tendencies of the temperature responses were well captured by the numerical analysis, as shown in Figure 5(b).

The measured and computed temperature profiles at the end of the first heating phase are compared in Figure 6. The measured pile temperature was nearly uniform along the pile shaft, except near the pile toe which is slightly further from the heat transfer pipe. In the numerical analysis, the temperature measured at the T2 location was used as the imposed boundary condition of the whole pile. In other word, the pile temperature in the finite element analysis was constant along the entire pile. As shown in Figure 5, this simplification can yield satisfactory results for soil temperature.

4.3. Thermal Displacement. The measured thermally induced displacement at the pile head is shown in Figure 7. The values predicted by the MC and BS models are also presented for comparison. As measured, the first heating phase caused a heave of $0.06 \mathrm{~mm}$. This value is smaller than the free expansion deformation $(\alpha \Delta \mathrm{TL}=0.33 \mathrm{~mm})$ if the pile toe is fixed. This difference indicates that there is a downward displacement at the pile toe during the heating process. During the cooling processes, the pile contracted and the pile head settled. The slope of the cooling phase is steeper than that of the heating phase; an irreversible settlement was observed for each thermal cycle. At the end of the test, the cumulative settlement was $0.14 \mathrm{~mm}$, which is approximately $43.8 \%$ of the settlement under mechanical loading $(0.32 \mathrm{~mm})$.

It can be seen from Figure 7 that the development of the thermally induced displacement at the pile head can be simulated reasonably by the BS model, in which the accumulation of irreversible strain during cyclic loading is considered. The computed additional settlement after three thermal cycles was $0.10 \mathrm{~mm}$. As thermal contraction of the sand skeleton was not accounted for in the numerical analysis, the settlement was slightly underestimated. For the MC model, the soil elements near the pile shaft were within the elastic domain under thermomechanical loading; thus, the temperature-displacement curve is linear. The pile head almost returned to the initial position after thermal cycles.

To further investigate the displacement pattern of the energy pile, two additional analyses (with the MC and BS models) were performed at the ultimate load predicted by each model. The predicted thermal displacements are shown in Figure 8. In these cases, the shaft resistance was fully mobilized and the stiffness of the soil was relatively small. Hence, the stress component transferred to the pile toe was more pronounced than that of the case with a small load. Because of the yield in the soil beneath the pile toe, a ratcheting displacement pattern was also predicted by the MC model. However, the amplitude of the irreversible settlement was only $0.1 \mathrm{~mm}$ (approximately $32.2 \%$ of that given by the $\mathrm{BS}$ model). This means that the cyclic behavior of soil should be considered in the analysis of energy piles.

4.4. Thermal Strain. The distributions of the thermal strain at the end of the $n$th heating period were compared with the numerical results in Figure 9 (compressive strain is taken as positive). Owing to the aforementioned shortcoming of the MC model, only the result of the BS model is presented. To account for thermal effects on the strain gauge, the raw measured values were corrected following the approach proposed by Goode and McCartney [24]. The thermal correction factor of each strain gauge was determined by a free expansion heating test on the pile. After thermal correction, the net thermal strain was calculated from the corrected value by subtracting the mechanical strain due to the pile head load. 


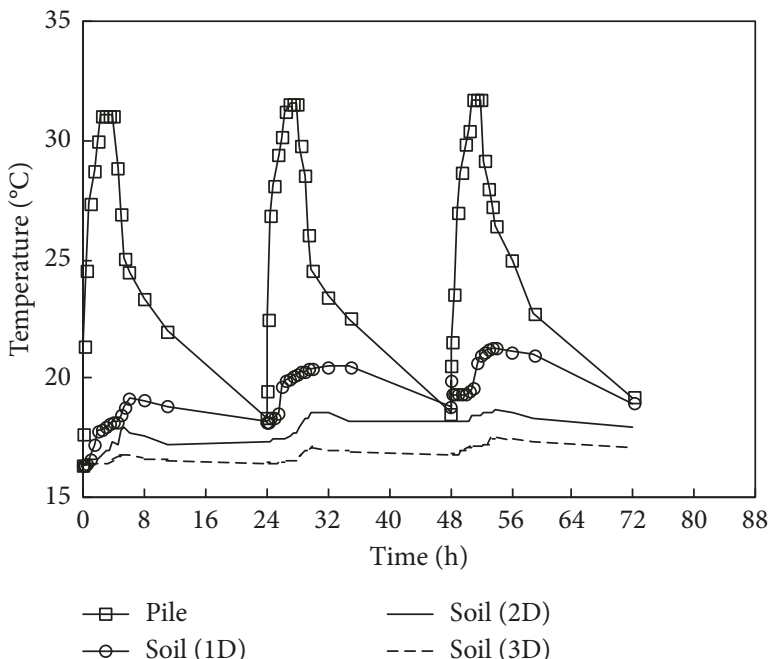

(a)

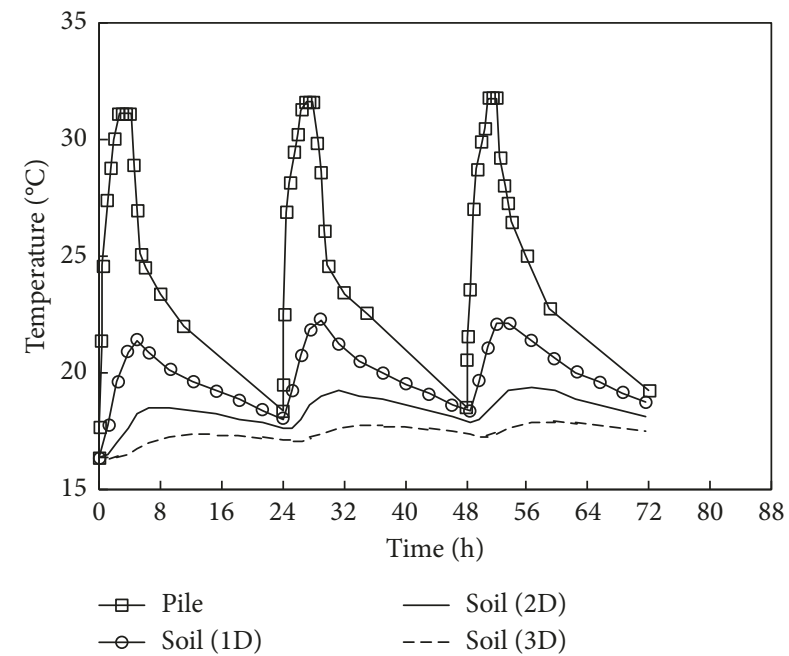

(b)

Figure 5: Temperature variation. (a) Measured. (b) Computed.

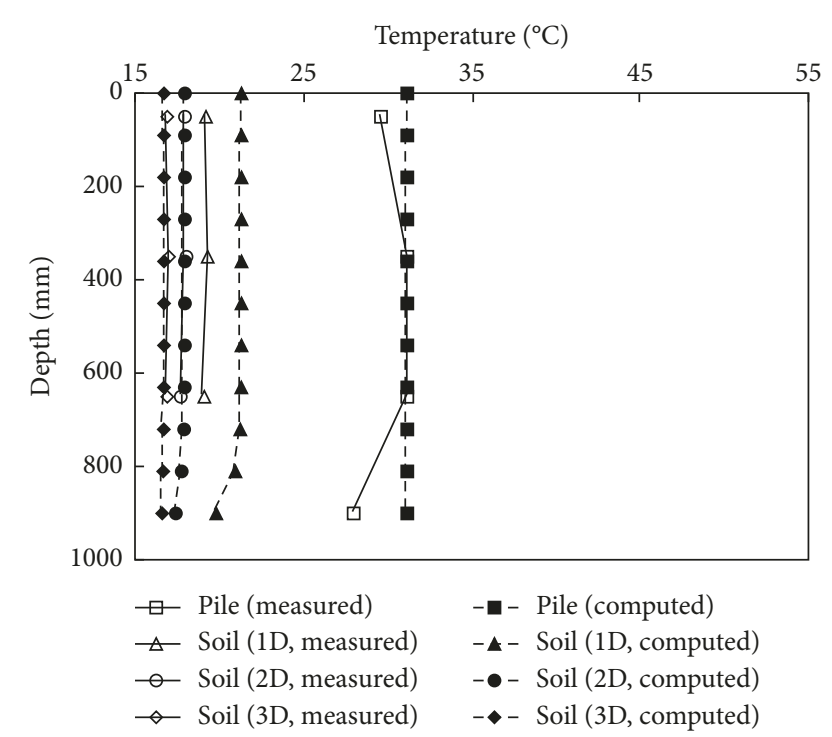

FIgURE 6: Temperature profiles.

It is observed that the thermal strains at the middle portions of the pile are slightly smaller than those at the lower and upper portions. This distribution pattern of thermal strain is consistent with that reported by Amatya et al. [4] for a free head pile. It is also noted that the thermal strain induced by heating decreased with thermal cycles, which implies that the axial force increased slightly with increasing thermal cycles.

\section{Numerical Sensitivity Analysis}

Although there are some differences between the simulation and observation results, the main characteristics of energy piles subjected to thermal cycles can be captured reasonably by the proposed numerical approach. Therefore, it can be

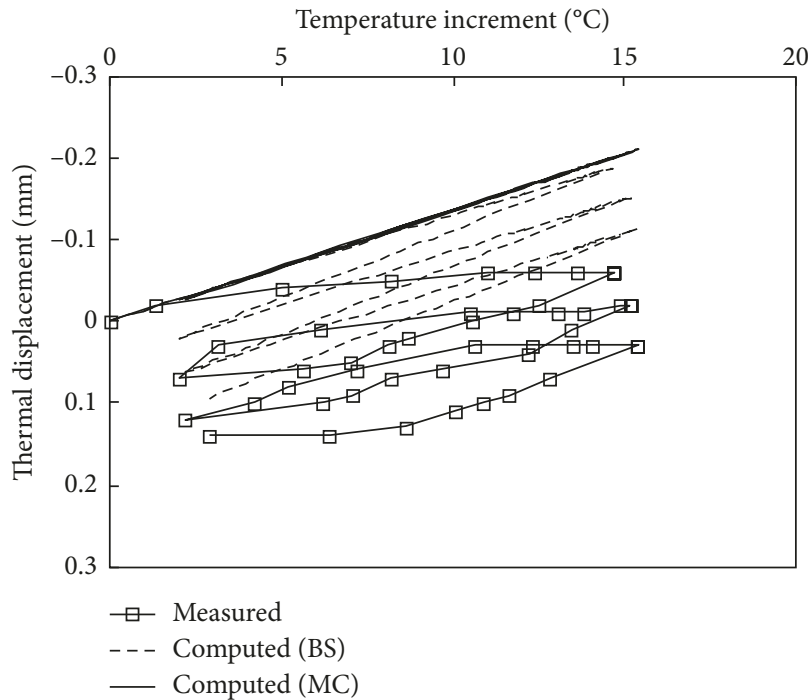

Figure 7: Thermally induced displacement at the pile head.

used to obtain a deeper insight into the long-term performance of energy piles.

\subsection{Numerical Details}

5.1.1. Numerical Analysis Plan. A sensitivity analysis was conducted to investigate the long-term performance of a typical concrete energy pile. The pile was $1.0 \mathrm{~m}$ in diameter and $20.0 \mathrm{~m}$ in length. Two ground conditions, i.e., loose sand and dense sand, were considered.

For each ground condition, three sets of analyses were carried out. In the first set of analyses, the pile was statically loaded to failure at a constant temperature. The ultimate pile resistance was determined based on the predicted loadsettlement relationship. 


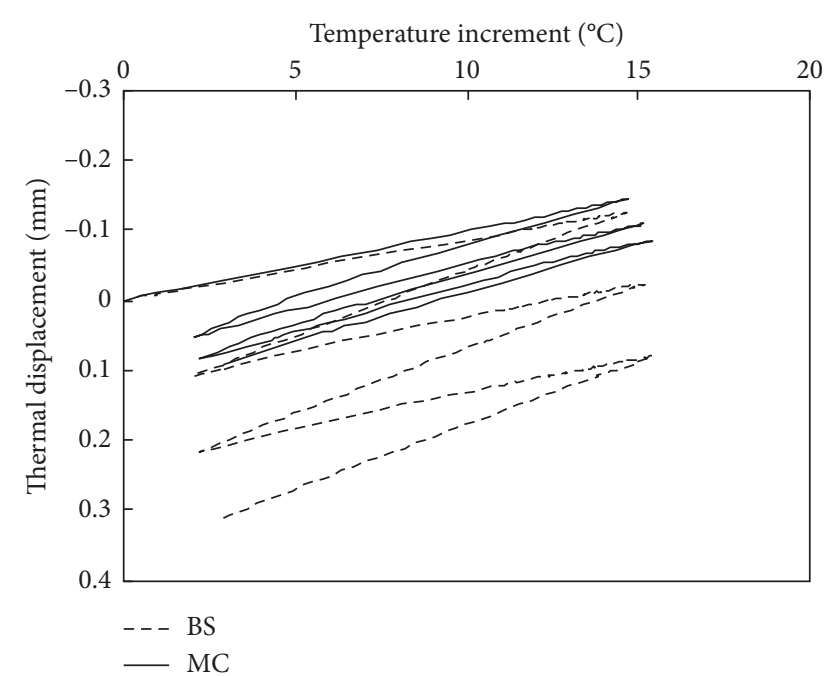

Figure 8: Predicted thermal displacement under the ultimate load.

For the second set of analyses, thermal cycles were applied at the working load level (with a factor of safety of 2.5). Two types of pile head fixities, i.e., a free head pile and a restrained head pile, were considered. The restrained pile considered in this study was an approximation of the single energy pile within a pile group consisting of energy and conventional piles. In this situation, the thermally induced displacement at the pile head is constrained by the raft and can be regarded as zero.

To evaluate the influence of the thermal cycles on the ultimate pile resistance, the pile was reloaded to failure in the third set of analyses.

5.1.2. Material Properties and Boundary Conditions. The pile was modeled using a linear elastic model, and the relevant parameters of which are given in Table 1. The soil was modeled using the BS model. The values of material constants for loose and dense Sacramento River sand [22] were used in the analyses (Table 2).

The coefficient of earth pressure at rest, $K_{0}$, was 0.5 . It should be noted that the pile was considered a bored pile, and thus installation effects were not considered in the analyses.

The initial temperature of the pile and ground was $15^{\circ} \mathrm{C}$. The temperature of the pile was set to change $\pm 20^{\circ} \mathrm{C} \mathrm{cy}$ clically. The temperature variation curve for one cycle is shown in Figure 10. Twenty cycles of thermal loading were applied in the study.

\subsection{Numerical Results}

\subsubsection{Pile Head Response}

(1) Free Head Pile. On the basis of the numerical results, the ultimate pile resistances were $5596 \mathrm{kN}$ (loose sand) and $35342 \mathrm{kN}$ (dense sand). By applying a factor of safety of 2.5, the design working loads were chosen as 2238 and $14137 \mathrm{kN}$ for the piles in the loose and dense sands, respectively.

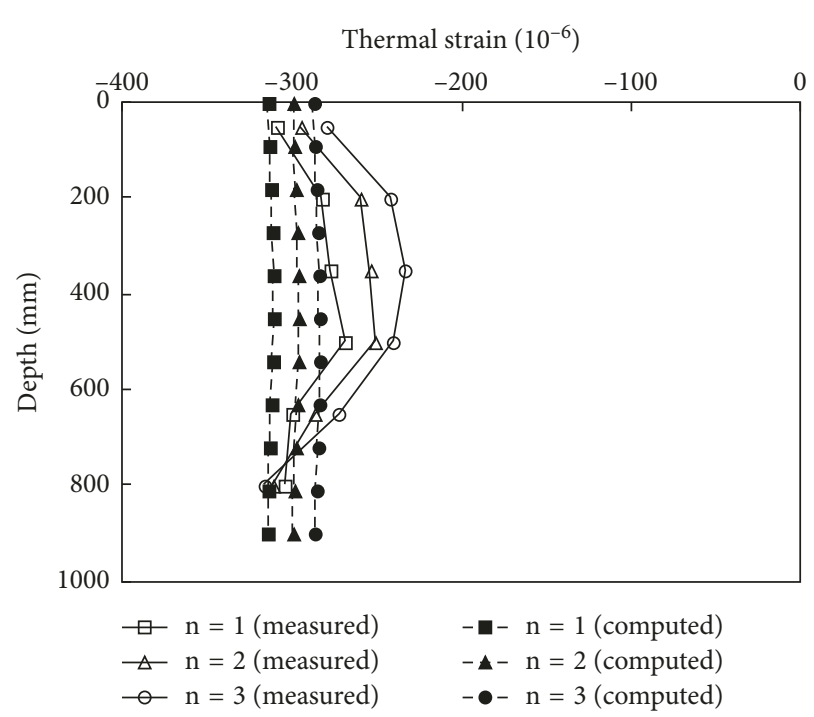

Figure 9: Thermal strain profile.

The corresponding settlements were 5.5 and $29.8 \mathrm{~mm}$, respectively.

The variations in pile head displacement with the number of thermal cycles are shown in Figure 11. In the figure, downward displacements are taken as positive. As expected, the pile expanded during heating and contracted during cooling. For the pile in the loose sand, the pile head heaved by $2.8 \mathrm{~mm}$ after the first heating. At the end of the following cooling period, the pile head was $3.2 \mathrm{~mm}$ lower than the initial position. Owing to the plastic soil strains developed below the pile tip, an irreversible settlement was observed at the pile head after completion of the first thermal cycle. The pile head settlement increased gradually to $13.1 \mathrm{~mm}$ after 20 cycles, which is approximately 2.4 times the initial static settlement caused by the mechanical load. The potential influence of the accumulated settlement on the serviceability of the pile and the structure should be considered in the design. For the energy pile in the dense sand, a similar displacement pattern was observed. Because the dense sand has a greater ability to resist cyclic loading, the increment of the pile settlement was smaller than that for the loose sand. The final settlement was 1.4 times the initial settlement.

(2) Restrained Head Pile. For the restrained pile, the pile head was fixed during the thermal cycles. Hence, the focus is on the variation in the reaction force at the pile head (Figure 12). The compressive axial forces were found to decrease with the number of cycles for the piles in both the loose and dense sands. The main reason for this phenomenon is that the soil experienced significant plastic strains induced by the cyclic loading, and thus the soil settled more than the pile. Therefore, a downdrag load (or negative shear stress) was induced along the interface of the pile and the soil. If the working load is small (for the case of the pile in loose sand), a tensile force develops at the pile head. The risk of tensile failure should be considered in the design. It is also worth mentioning that, in a pile group, a reduction in the pile head reaction generates an additional load on the 


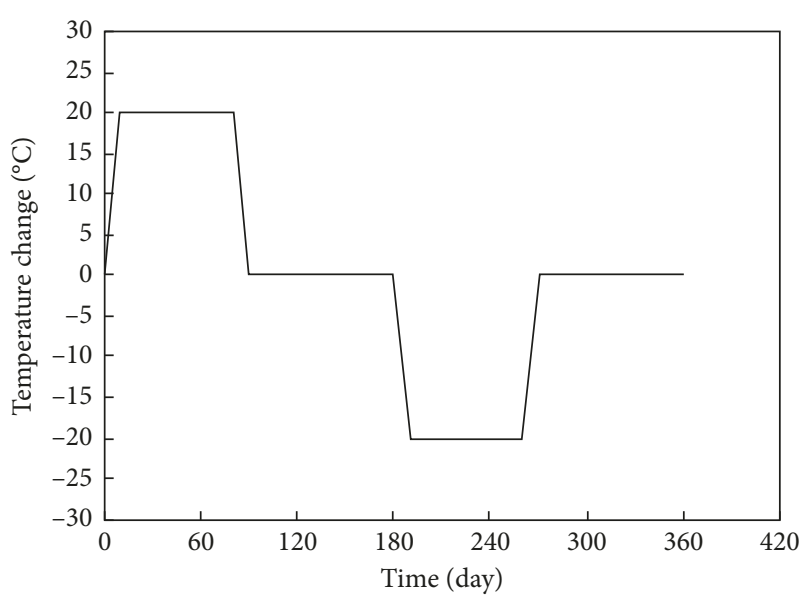

FIgURE 10: Temperature variation of the pile in one cycle.

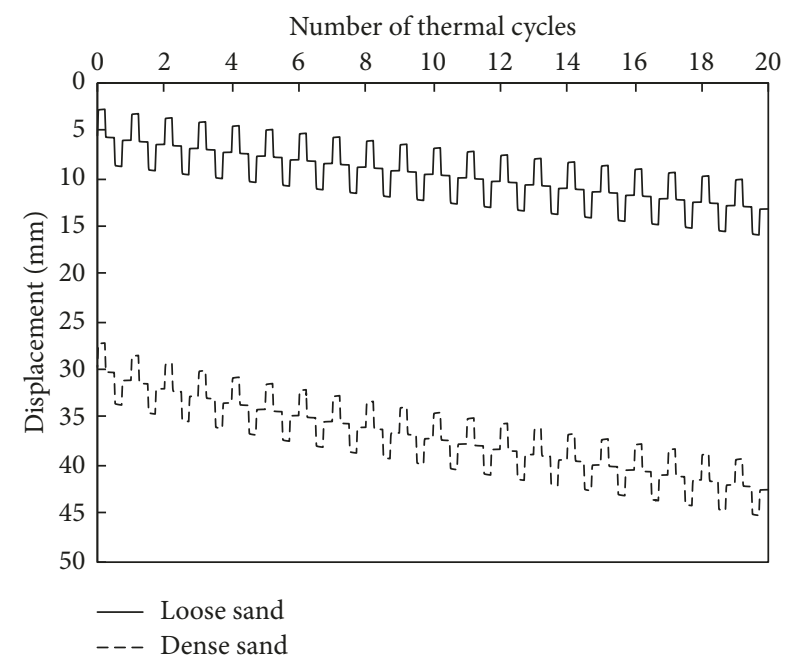

FIGURE 11: Variations in pile head displacement for the free head pile.

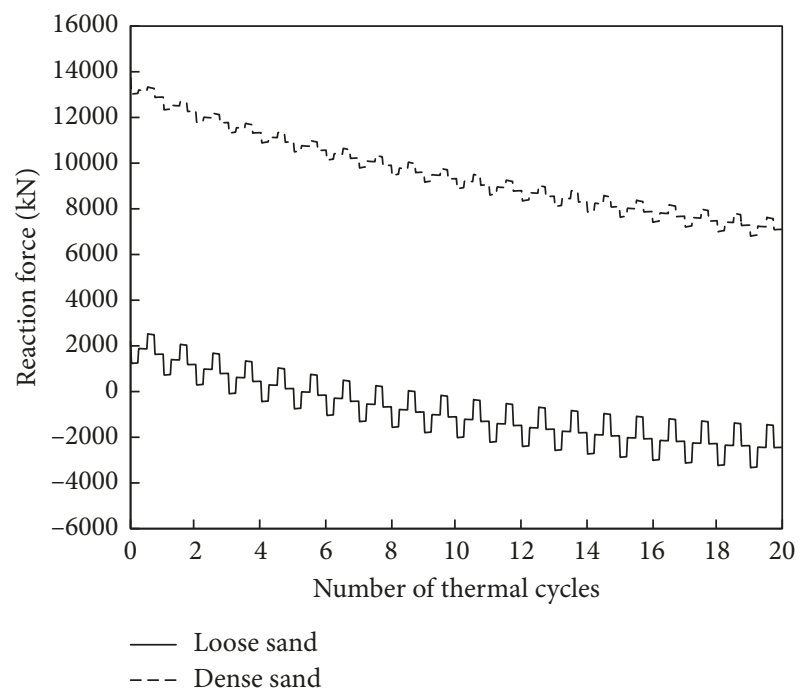

FIGURE 12: Variations in the reaction force for the restrained head pile.

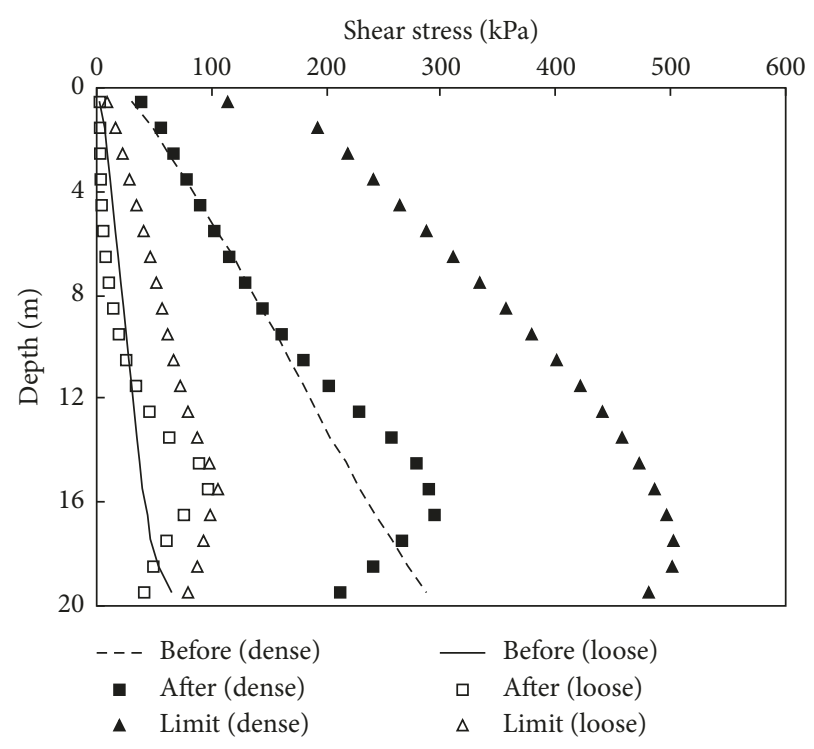

FIGURE 13: Distribution of the shear stress at the pile-soil interface for the free head pile.

neighboring pile. The redistribution of stresses should also be considered.

\subsubsection{Shear Stress at the Pile-Soil Interface}

(1) Free Head Pile. The distributions of the shear stress before and after the thermal cycles are shown in Figure 13. In addition, the limit shear stresses of the reloading stage are given for reference. The shear stress-shear strain curves of the soil elements adjacent to the pile shaft at $z=15 \mathrm{~m}$ and $18 \mathrm{~m}$ depths during and after thermal cycles are shown in Figure 14.

It is observed that there are different tendencies in shear stress changes for the soils at different depths. After the thermal cycles, the shear stresses between the depths of 12 and $18 \mathrm{~m}$ increased, while the shear stresses at other depths decreased. This occurrence can be attributed to the specific relative pilesoil displacement mode at these locations. As shown in Figure 15, the location of the null point, characterized by zero thermally induced pile displacement, can be identified by comparing the pile displacement distributions at different stages. For the free head pile in the loose sand, the null point of the first heating phase was at a depth of $14.2 \mathrm{~m}$ (indicated as NP-H in Figure 15). During the subsequent cooling period, the deeper part of the pile-soil interface underwent unloading while the upper part underwent loading. Owing to the difference between the loading and unloading stiffness, the pile's contraction mobilized a greater resistance over the lower section, and thus the null point of the cooling (NP-C) was deeper that of the heating phase, at approximately $15.8 \mathrm{~m}$ deep. For the pile in the dense sand, the depth of the null point was $13.2 \mathrm{~m}$ during heating and $16.8 \mathrm{~m}$ during cooling. During the subsequent cycles, the distance between the null point of heating and that of cooling increased slightly.

Below the null point, the heating induced expansion pushed the pile down and led to an increase in the shear stress. For the upper part of the pile, the upward expansive 


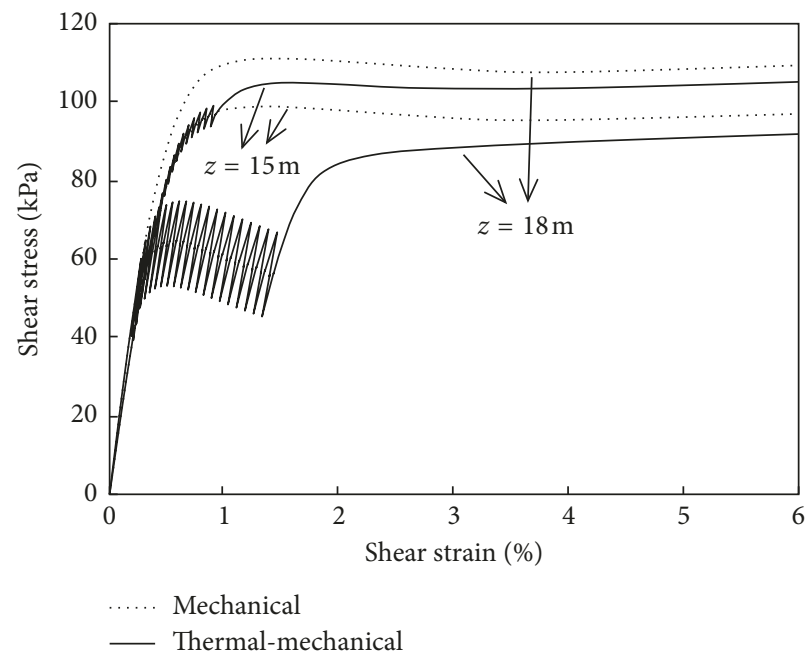

(a)

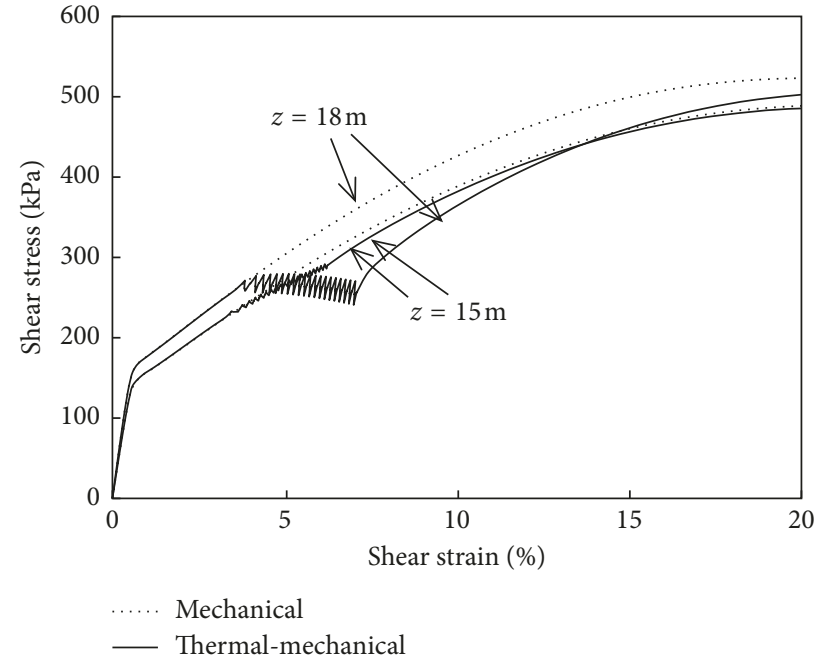

(b)

Figure 14: Development of shear stress at pile-soil interface for the free head pile. (a) Pile in loose sand. (b) Pile in dense sand.

deformation decreased the relative pile-soil displacement and the shear stress. During the process of cooling, an opposite variation in shear stress occurred. As expected, the shear stresses at these locations changed cyclically. Owing to the accumulation of plastic strains in each cycle, the shear stress at $z=18 \mathrm{~m}$ decreased with the number of thermal cycles. The reduction in stress was more apparent for the pile in the loose sand owing to the soil contraction.

Because the null point of cooling was deeper than that of heating, the shear deformation of the soil between these two points always increases during the heating/cooling cycles. Hence, the soil at $z=15 \mathrm{~m}$ sheared monotonically and the response was similar to that of the pile subjected to the mechanical loading case.

(2) Restrained Head Pile. The distributions of and variations in the shear stresses are given in Figures 16 and 17, respectively. Because the response at $z=15 \mathrm{~m}$ was similar to that at $z=18 \mathrm{~m}$, only the results of the soil at $z=18 \mathrm{~m}$ are given in Figure 17. In the case of the restrained head pile, because the null point of the heating and cooling was fixed at the pile head, the shear stresses along the entire length of the pile simultaneously increased during heating and decreased during cooling. The reduction in the shear stresses after each thermal cycle was evident. Because the thermally induced displacement of the pile increased with the distance to the null point, the variations in soil stresses were more apparent at deeper locations. Owing to the larger thermal displacement, the decrease in the shear stress was more obvious than that in the free head pile case. For the pile in loose sand, a negative shear stress was even observed after thermal cycles.

\subsubsection{Ultimate Pile Resistance after Thermal Cycles}

(1) Free Head Pile. To investigate the effect of thermal cycles on the long-term capacity, the load settlement curves with and without the thermal cycles are compared in Figure 18.

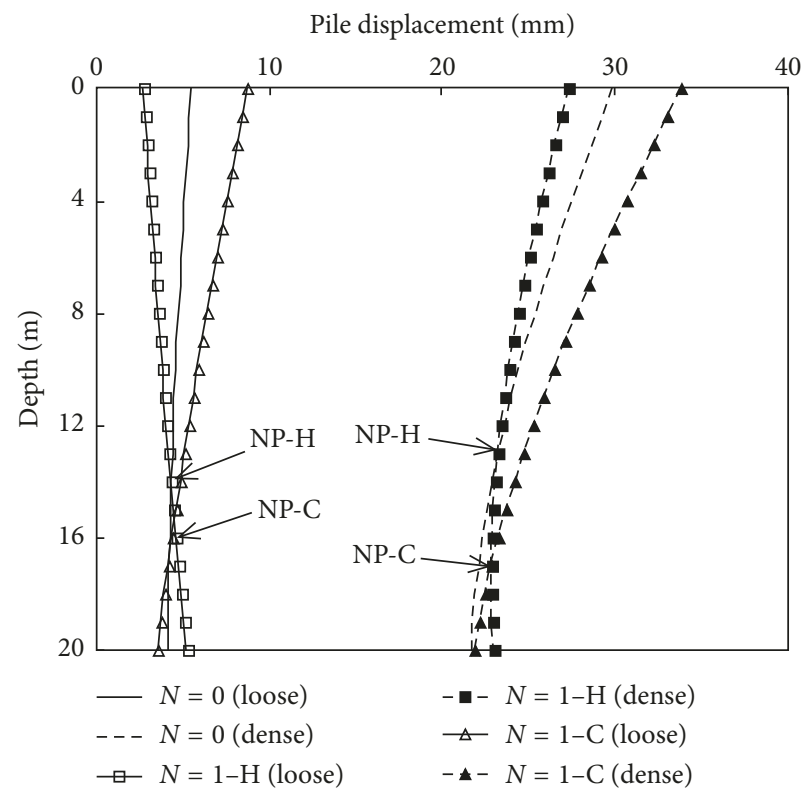

FIgURE 15: Location of the null point for the free head pile.

For the free head in loose sand, referring to Figure 14(a), the soil element at $z=18 \mathrm{~m}$ was contractive under the applied soil parameters and the specific stress condition. The change in the soil state after thermal cycles decreased the limit shear stress from 115.3 to $88.2 \mathrm{kPa}$. For the soil element at $z=15 \mathrm{~m}$, because the soil was nearly sheared monotonically during thermal cycles, the trajectory of the shear stress closely approximated that under the static load. When reloaded to failure, the ultimate shear resistance increased from $97.2 \mathrm{kPa}$ (reference case) to $106.9 \mathrm{kPa}$ owing to the increased horizontal stress after thermal cycles. The increase in the shear stress near this point partially compensated for the friction fatigue at other depths. The magnitude of the total resistance did not change considerably. After 20 


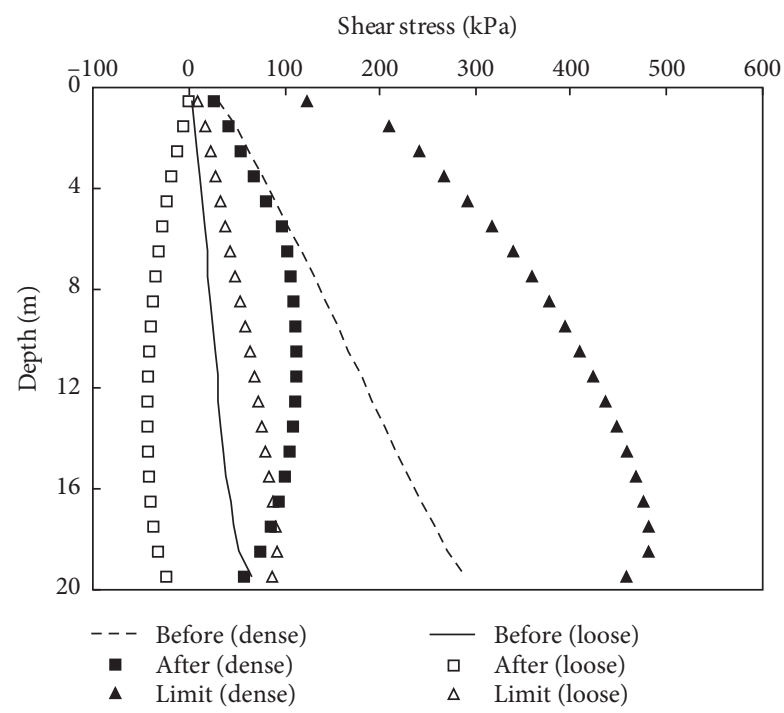

FIGURE 16: Distribution of shear stress at the pile-soil interface for the restrained head pile.

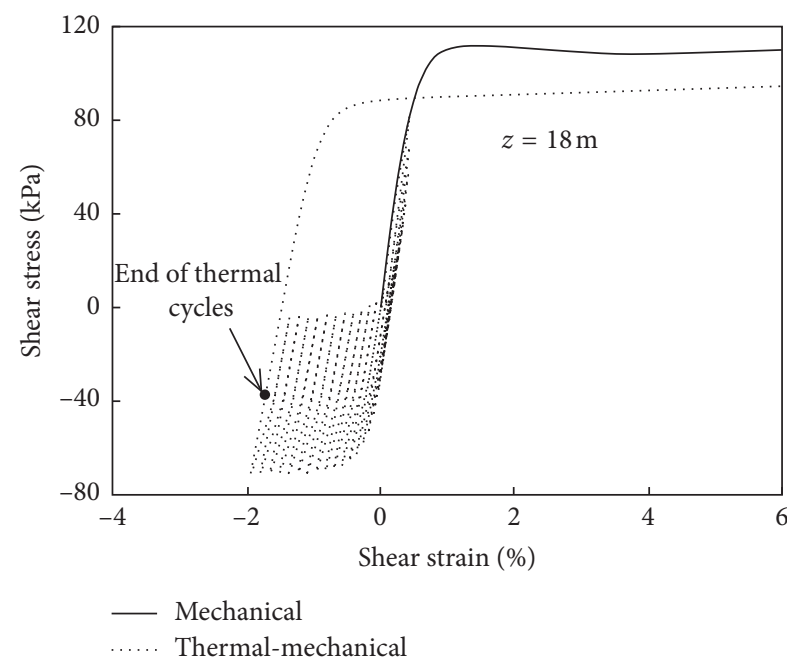

(a)

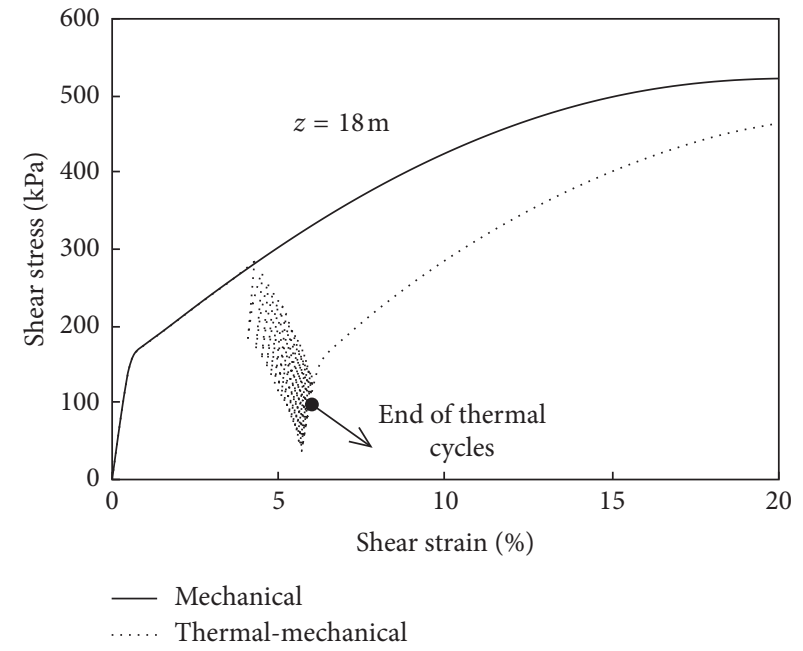

(b)

Figure 17: Development of shear stress at pile-soil interface for the restrained head pile. (a) Pile in loose sand. (b) Pile in dense sand.

thermal cycles, the decrease in the total ultimate resistance was $13 \%$.

For the free head pile in dense sand, the ultimate shear stress mobilized at $z=18 \mathrm{~m}$ was $505.8 \mathrm{kPa}$, which is close to that in the reference case without thermal cycles $(522.2 \mathrm{kPa})$. This implies that the limit shear stress was dominated by the soil dilatancy during the reloading stage, and the effect of the thermal cycles was small. The decrease in the total ultimate resistance was $3 \%$.

It should be noted that owing to the degradation effect at the pile-soil interface and the change in the soil state, the pile displacement required to mobilize the ultimate resistance increased after thermal cycles. The overall stiffness of the pile-soil system decreased slightly after thermal cycles. Taking into account the accumulated settlement during the thermal operation, the long-term performance of the energy pile seems to be controlled predominantly by the settlement rather than the capacity.

(2) Restrained Head Pile. The load settlement curves of restrained head piles in the loose and dense sands are also plotted in Figure 18. Although negative shear stress may be induced by the application of thermal cycles, the pile moved down relative to the soil in the subsequent reloading stage, and the negative shear stress was eliminated. In a similar manner to that observed for free head piles, the reductions in the horizontal and mobilized shear stresses recovered to a large extent in the subsequent reloading. The total resistances were reduced by $16 \%$ and $3 \%$ for the piles in the loose and dense sands, respectively. 


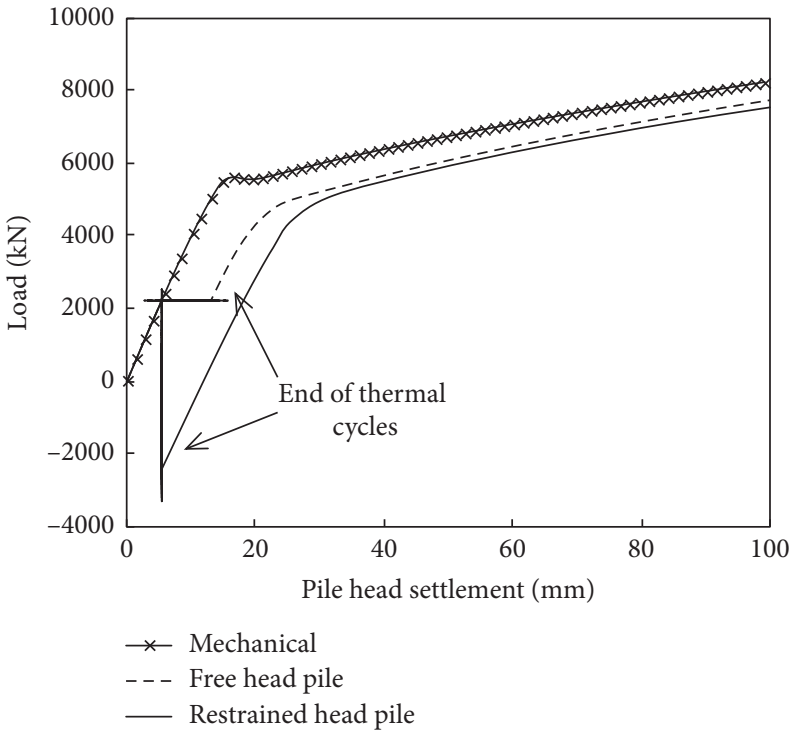

(a)

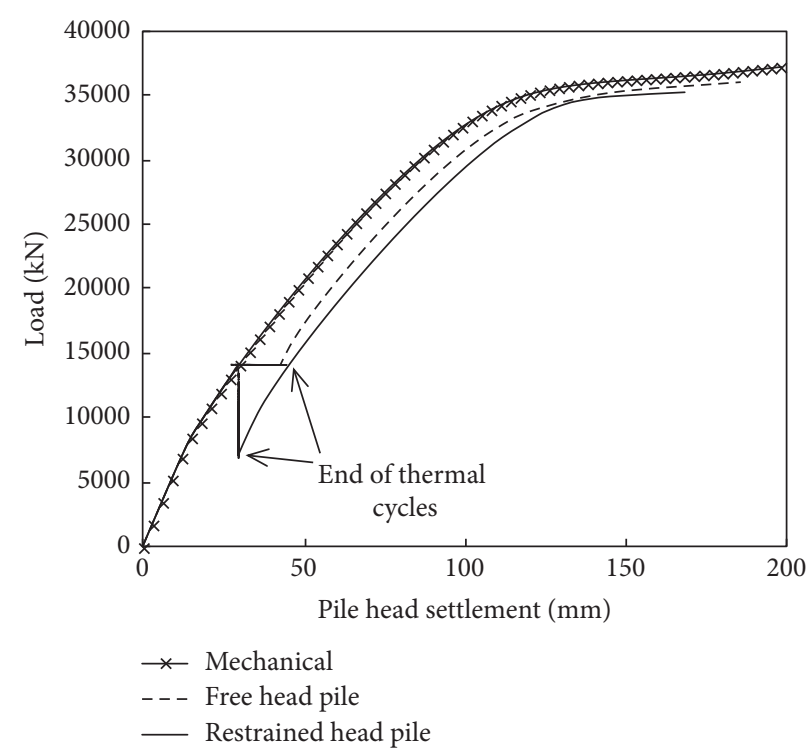

(b)

Figure 18: Comparison of load settlement curves of piles with and without thermal cycles. (a) Pile in loose sand. (b) Pile in dense sand.

\section{Conclusions}

In this study, a laboratory-scale model test was carried out to investigate the behavior of energy piles subjected to thermal cycles. The experimental results were analyzed and used to validate the finite element model. Then, numerical sensitivity analyses were performed to gain deeper insight into the long-term performance of energy piles with different soil and pile head restraint conditions. The main conclusions are as follows:

(1) The experimental result of a free head pile subjected to thermal cycles suggests that the cyclic temperature variation induces irreversible pile settlements. The axial force of the pile increased slightly with the number of thermal cycles.

(2) The proposed sequentially coupled numerical approach can reasonably capture the main characteristics of energy piles subjected to thermal cycles. A suitable model to describe the cyclic behavior of the soil is essential.

(3) The results of the numerical sensitivity analyses showed that the null point of the cooling phase for the free head pile was deeper than that of the heating phase. The shear stress trapped between these two points increased almost monotonically, while the skin forces at other depths decreased gradually with the number of thermal cycles. For the restrained head pile, the skin forces along the entire length of the pile varied simultaneously as the null point was fixed at the pile head. After each thermal cycle, a reduction in skin forces was observed.

(4) The ultimate pile resistance after thermal cycles did not decrease significantly. The long-term performance of the energy pile seems to be controlled predominantly by the settlement rather than the capacity. The presented results are specific to the simulated cases. This should be considered when designing energy piles in other conditions.

\section{Data Availability}

The data used to support the findings of this study are included within the article.

\section{Conflicts of Interest}

The authors declare that they have no conflicts of interest.

\section{Acknowledgments}

This work was supported by the National Natural Science Foundation of China (grant number 51778557) and the Qing Lan Project (grant number 20160512) of the Jiangsu Province Government.

\section{References}

[1] H. Brandl, "Energy foundations and other thermo-active ground structures," Geotechnique, vol. 56, no. 2, pp. 81-122, 2006.

[2] L. Laloui, M. Nuth, and L. Vulliet, "Experimental and numerical investigations of the behaviour of a heat exchanger pile," International Journal for Numerical and Analytical Methods in Geomechanics, vol. 30, no. 8, pp. 763-781, 2006.

[3] P. J. Bourne-Webb, B. L. Amatya, K. Soga, T. Amis, C. Davidson, and P. Payne, "Energy pile test at Lambeth College, London: geotechnical and thermodynamic aspects of pile response to heat cycles," Géotechnique, vol. 59, no. 3, pp. 237-248, 2009. 
[4] B. L. Amatya, K. Soga, P. J. Bourne-Webb, T. Amis, and L. Laloui, "Thermo-mechanical behaviour of energy piles," Géotechnique, vol. 62, no. 6, pp. 503-519, 2012.

[5] A. Di Donna and L. Laloui, "Numerical analysis of the geotechnical behaviour of energy piles," International Journal for Numerical and Analytical Methods in Geomechanics, vol. 39, no. 8, pp. 861-888, 2015.

[6] A. Kalantidou, A. M. Tang, J. M. Pereira, and G. Hassen, "Preliminary study on the mechanical behaviour of heat exchanger pile in physical model," Géotechnique, vol. 62, no. 11, pp. 1047-1051, 2012.

[7] N. Yavari, A. M. Tang, J. M. Pereira, and G. Hassen, "Experimental study on the mechanical behaviour of a heat exchanger pile using physical modelling," Acta Geotechnica, vol. 9, no. 3, pp. 385-398, 2014.

[8] V. T. Nguyen, A. M. Tang, and J. M. Pereira, "Long-term thermo-mechanical behavior of energy pile in dry sand," Acta Geotechnica, vol. 12, no. 4, pp. 729-737, 2017.

[9] J. S. McCartney and J. E. Rosenberg, "Impact of heat exchange on side shear in thermo-active foundations," in Proceedings of Geo-Frontiers 2011: Advances in Geotechnical Engineering, pp. 488-498, ASCE, Dallas, TX, USA, March 2011.

[10] C. W. W. Ng, C. Shi, A. Gunawan, L. Laloui, and H. L. Liu, "Centrifuge modelling of heating effects on energy pile performance in saturated sand," Canadian Geotechnical Journal, vol. 52, no. 8, pp. 1045-1057, 2014.

[11] M. A. Stewart and J. S. McCartney, "Centrifuge modeling of soil-structure interaction in energy foundations," Journal of Geotechnical and Geoenvironmental Engineering, vol. 140, no. 4, article 04013044, 2013.

[12] C. W. W. Ng, C. Shi, A. Gunawan, and L. Laloui, "Centrifuge modelling of energy piles subjected to heating and cooling cycles in clay," Geotechnique Letters, vol. 4, no. 4, pp. 310-316, 2014.

[13] A. F. R. Loria, A. Gunawan, C. Shi, L. Laloui, and C. W. Ng, "Numerical modelling of energy piles in saturated sand subjected to thermo-mechanical loads," Geomechanics for Energy and the Environment, vol. 1, pp. 1-15, 2015.

[14] S. Jeong, H. Lim, J. K. Lee, and J. Kim, "Thermally induced mechanical response of energy piles in axially loaded pile groups," Applied Thermal Engineering, vol. 71, no. 1, pp. 608-615, 2014.

[15] A. Di Donna, A. F. R. Loria, and L. Laloui, "Numerical study of the response of a group of energy piles under different combinations of thermo-mechanical loads," Computers and Geotechnics, vol. 72, pp. 126-142, 2016.

[16] R. Saggu and T. Chakraborty, "Cyclic thermo-mechanical analysis of energy piles in sand," Geotechnical and Geological Engineering, vol. 33, no. 2, pp. 321-342, 2015.

[17] M. E. Suryatriyastuti, H. Mroueh, and S. Burlon, "A load transfer approach for studying the cyclic behavior of thermoactive piles," Computers and Geotechnics, vol. 55, pp. 378-391, 2014.

[18] M. E. Suryatriyastuti, S. Burlon, and H. Mroueh, "On the understanding of cyclic interaction mechanisms in an energy pile group," International Journal for Numerical and Analytical Methods in Geomechanics, vol. 40, no. 1, pp. 3-24, 2016.

[19] K. Fei, W. Hong, and J. Qian, "Numerical analysis of the long-term performance of energy piles in sand," in Proceedings of Pavement Materials and Associated Geotechnical Aspects of Civil Infrastructures (GeoChina 2018), Sustainable Civil Infrastructures, W. Steyn, I. Holleran, and B. Nam, Eds., pp. 57-72, Springer, Zhejiang, China, July 2019.
[20] C. W. Ng, Q. J. Ma, and A. Gunawan, "Horizontal stress change of energy piles subjected to thermal cycles in sand," Computers and Geotechnics, vol. 78, pp. 54-61, 2016.

[21] C. S. Desai, H. V. Phan, and S. Sture, "Procedure, selection and application of plasticity models for a soil," International Journal for Numerical and Analytical Methods in Geomechanics, vol. 5, no. 3, pp. 295-311, 1981.

[22] J. P. Bardet, "Bounding surface plasticity model for sands," Journal of Engineering Mechanics, vol. 112, no. 11, pp. 11981217, 1986.

[23] R. B. Brinkgreve, "Selection of soil models and parameters for geotechnical engineering application," in Proceedings of Soil Constitutive Models: Evaluation, Selection, and Calibration, pp. 69-98, ASCE, Austin, TX, USA, January 2005.

[24] J. C. Goode III and J. S. McCartney, "Centrifuge modeling of end-restraint effects in energy foundations," Journal of Geotechnical and Geoenvironmental Engineering, vol. 141, no. 8, article 04015034, 2015. 


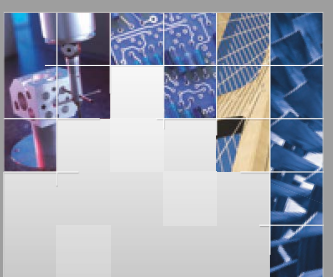

\section{Enfincering}
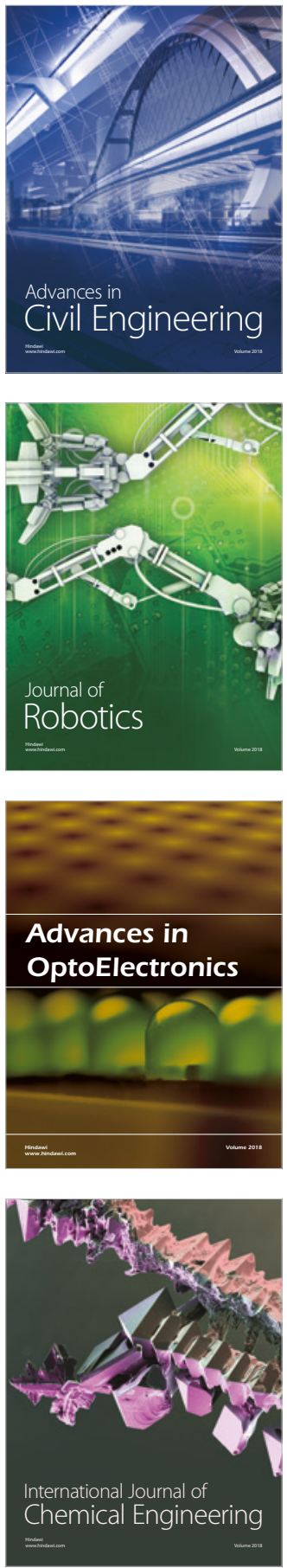

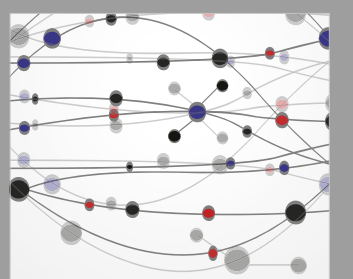

\section{Rotating \\ Machinery}

The Scientific World Journal

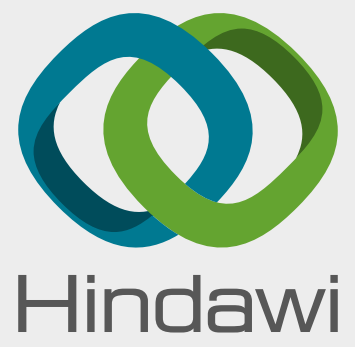

Submit your manuscripts at

www.hindawi.com
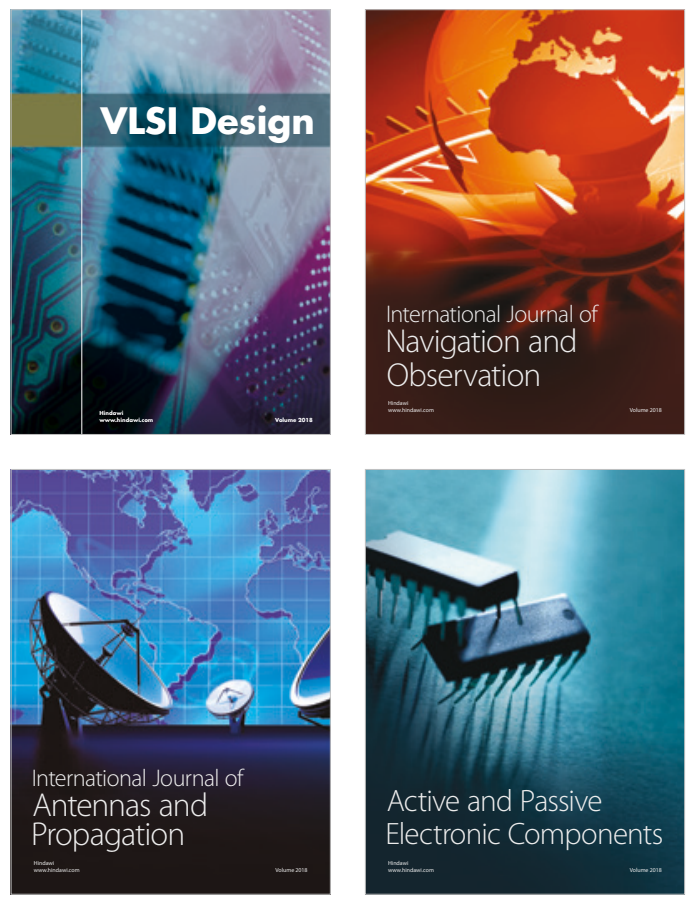
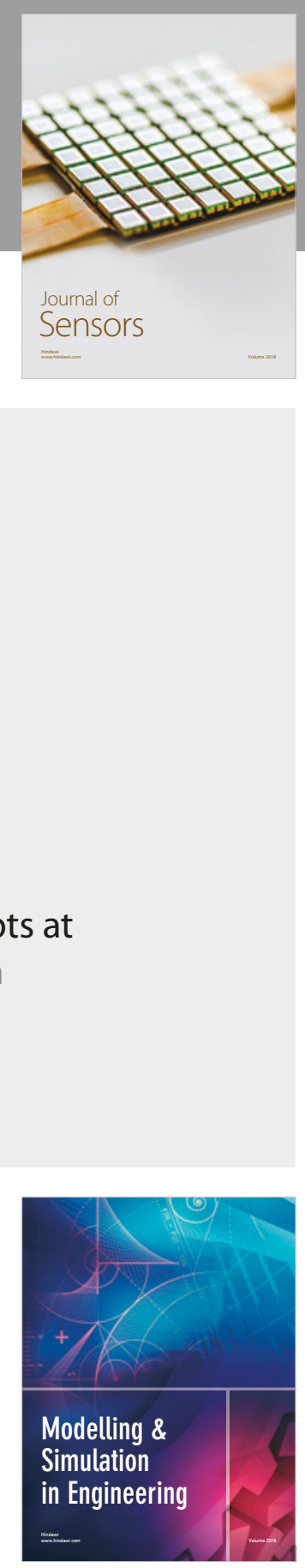

\section{Advances \\ Multimedia}
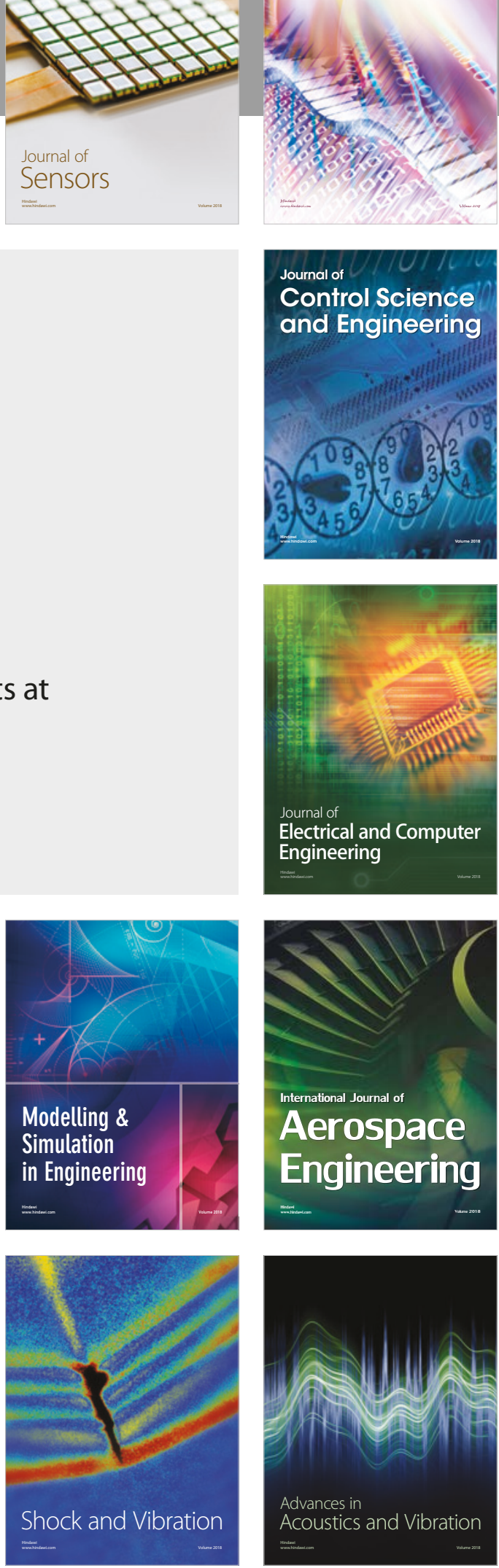